\title{
Cerebral blood flow and metabolism in children with severe head injuries. Part 2: cerebrovascular resistance and its determinants
}

\author{
P M Sharples, D S F Matthews, J A Eyre
}

\begin{abstract}
It has been proposed that in children with severe head injuries the cerebral circulation does not respond appropriately to normal physiological control mechanisms, making children more susceptible than adults to low cerebrovascular resistance, increased cerebral blood flow (cerebral hyperaemia), and raised intracranial pressure. To investigate this issue, 122 serial measurements of cerebrovascular resistance in 17 children with severe head injuries have been performed and related to cerebral perfusion pressure, arterial $\mathrm{CO}_{2}\left(\mathrm{PaCO}_{2}\right)$, arterial oxygen content $\left(\mathrm{Ao}_{2}\right)$, and the cerebral metabolic rate of oxygen $\left(\mathrm{CMRo}_{2}\right)$.

Cerebrovascular resistance values (mean (SD) $1.54(0.61) \mathrm{mm} \mathrm{Hg.ml} \mathbf{m}^{-1} .100$ g.min) were normal or raised in most cases; 71 values $(58 \%)$ were within the normal range, 39 (32\%) above the upper limit, and only $12(10 \%)$ below the lower limit. There was a significant correlation between cerebral perfusion pressure and cerebrovascular resistance $(r=0.32, p=$ $0 \cdot 0003$ ), suggesting preservation of pressure autoregulation. This correlation was absent in four of the five children who died or survived with severe handicap. Analysis by multilevel modelling indicated that, as in normal subjects, $\mathbf{C M R O}{ }_{2}$, CPP, $\mathbf{A O}_{2}, \mathbf{P a C O}_{2}$, and cerebrovenous $\mathbf{p H}$ were important independent determinants of cerebrovascular resistance.

The results indicate that normal cerebrovascular reactivity is often preserved in children with severe head injuries but may be impaired in the most severely injured patients.
\end{abstract}

\section{(F Neurol Neurosurg Psychiatry 1995;58:153-159)}

Keywords: head injury; cerebrovascular resistance; cerebral blood flow; arterial oxygen content.

Paediatric Neurology Research Unit, Department of Child Health, University of Newcastle upon Tyne, Newcastle upon Tyne NE2 4HH, UK P M Sharples D S F Matthews J A Eyre

Correspondence to: Dr Sharples, Institute of Child Health, Bristol Hospital for Sick Children, St Michael's Hill, Bristol BS2 8BJ, UK.

Received 10 August 1993 and in revised form

2 March 1994.

Accepted 29 March 1994 for the regulation of cerebral blood flow and cerebral blood volume in children with severe head injuries is essential to rational management. ${ }^{1}$ In a normal subject, the cerebral vascular bed adjusts (autoregulates) cerebral blood flow by altering cerebrovascular resistance to maintain a sufficient supply of oxygen and glucose to meet the brain's metabolic needs, despite changes in perfusion pressure.

Data obtained in adult patients indicate that cerebral autoregulatory mechanisms are often disturbed after head injury, ${ }^{2-4}$ but there is little published information available about children. Indeed, only one previous paper describes the measurement of cerebrovascular resistance in children with severe head injuries. ${ }^{5}$ Despite this lack of detailed information it has been proposed, on the basis of studies of cerebral blood flow in small numbers of head injured children, that hyperaemia and vasodilation represent "a ubiquitous response of the paediatric brain to trauma". ${ }^{6}$

The aims of this study were firstly, to explore whether cerebrovascular resistance is responsive to normal physiological mechanisms in children with severe head injuries and secondly, to determine if the overall level of cerebrovascular resistance is abnormally low in these patients.

\section{Patients and methods}

PATIENTS

Ethical approval for the project had been granted by the local ethics committee, and informed written consent was obtained from a parent or guardian. The study patients were the 17 children, of the 21 described in our previous paper, in whom measurements of cerebral blood flow and metabolism were performed in conjunction with intracranial pressure monitoring.

Table 1 gives details of the children. The mean age was 7 (range 2-16) years. Ten $(67 \%)$ were boys. The median Glasgow coma score $^{8}$ was 6 (range 3-8). Neurological outcome in all the children was scored between 12-36 months after injury, by an adaptation of the scales employed by Berger et al in their study of children with head injuries ${ }^{9}$ and Tasker et al in their study of paediatric nontraumatic coma. ${ }^{10}$ For the purposes of analysis, the children were divided into two groups-namely, those in whom outcome was good or moderate and those who died or survived with severe disabilities. ${ }^{7}$

\section{METHODS}

Measurement of cerebral blood flow and metabolism paper. ${ }^{7}$ Serial measurements were made of cerebral blood flow and cerebral metabolic rate for oxygen $\left(\mathrm{CMRO}_{2}\right)$ as previously described. ${ }^{11} 12$ At the time that each measurement was performed, arterial blood $(0.5 \mathrm{ml})$ was withdrawn for blood gas analysis and measurement of arterial oxygen content $\left(\mathrm{AO}_{2}\right)$ and cerebrovenous lactate concentration. ${ }^{13}$ The coefficient of variation of repeated measurements of whole blood lactate was $11 \%$. 
Table 1 Clinical details of the 17 comatose children

\begin{tabular}{|c|c|c|c|c|c|c|c|}
\hline Case & Age (y) & Sex & $\begin{array}{l}\text { Symbol } \\
\text { (as used in figs) }\end{array}$ & GCS & Mean $C V R$ & $C T$ appearance & Outcome \\
\hline $\begin{array}{r}1 \\
2 \\
3 \\
4 \\
5 \\
6 \\
7 \\
8 \\
9 \\
10 \\
11 \\
12 \\
13 \\
14 \\
15 \\
16 \\
17\end{array}$ & $\begin{array}{r}9 \\
16 \\
16 \\
2 \\
3 \\
12 \\
8 \\
2 \\
2 \\
3 \\
5 \\
6 \\
7 \\
4 \\
7 \\
8 \\
9\end{array}$ & $\begin{array}{l}M \\
F \\
F \\
M \\
M \\
M \\
F \\
M \\
M \\
M \\
F \\
M \\
M \\
M \\
M \\
M \\
F\end{array}$ & 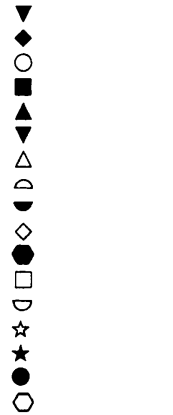 & $\begin{array}{l}6 \\
8 \\
7 \\
8 \\
6 \\
4 \\
6 \\
8 \\
8 \\
6 \\
4 \\
8 \\
6 \\
3 \\
8 \\
4 \\
6\end{array}$ & $\begin{array}{l}1.61 \\
1.81 \\
1.61 \\
1.24 \\
1.37 \\
2.09 \\
0.97 \\
1.04 \\
2.22 \\
1.52 \\
2.56 \\
1.25 \\
2.96 \\
1.38 \\
1.84 \\
1.58 \\
1.58\end{array}$ & $\begin{array}{l}\text { Diffuse swelling } \\
\text { Diffuse swelling } \\
\text { Diffuse swelling } \\
\text { Focal contusion } \\
\text { Focal contusion } \\
\text { Diffuse swelling } \\
\text { Diffuse swelling } \\
\text { Frontal contusions } \\
\text { EDH } \\
\text { DAI } \\
\text { Diffuse swelling/SDH } \\
\text { DAI } \\
\text { Normal } \\
\text { DAI } \\
\text { Focal contusion } \\
\text { Diffuse swelling } \\
\text { Diffuse swelling/DAI }\end{array}$ & $\begin{array}{l}\text { Good } \\
\text { Good } \\
\text { Good } \\
\text { Good } \\
\text { Good } \\
\text { Moderate } \\
\text { Moderate } \\
\text { Moderate } \\
\text { Moderate } \\
\text { Moderate } \\
\text { Moderate } \\
\text { Moderate } \\
\text { Moderate } \\
\text { Died } \\
\text { Died } \\
\text { Poor } \\
\text { Poor }\end{array}$ \\
\hline
\end{tabular}

GCS = Glasgow coma score on admission; $\mathrm{CVR}=$ cerebrovascular resistance; $\mathrm{CT}=$ computed tomography; EDH $=$ extradural haematoma; DAI = diffuse axonal injury; $\mathrm{SDH}=$ subdural haematoma.

Figure 1 Cerebrovascular resistance (CVR) v age

(A), Glasgow coma score (B), and time after injury (C). In $(A)$ and $(B)$ the filled circles represent the mean CVR obtained in an individual patient and in $(A)$ the vertical lines represent the range of results obtained from each patient. In $(C)$ each line represents the serial measurements of CVR obtained from each patient. The shaded area in each graph represents the limits of the normal range $( \pm 2$ $S D$ from the mean) published by Scheinberg and Stead. ${ }^{15}$
Measurement of cerebral perfusion pressure and cerebrovascular resistance

Intracranial pressure was measured in all the patients; in four, via a fluid filled ventricular
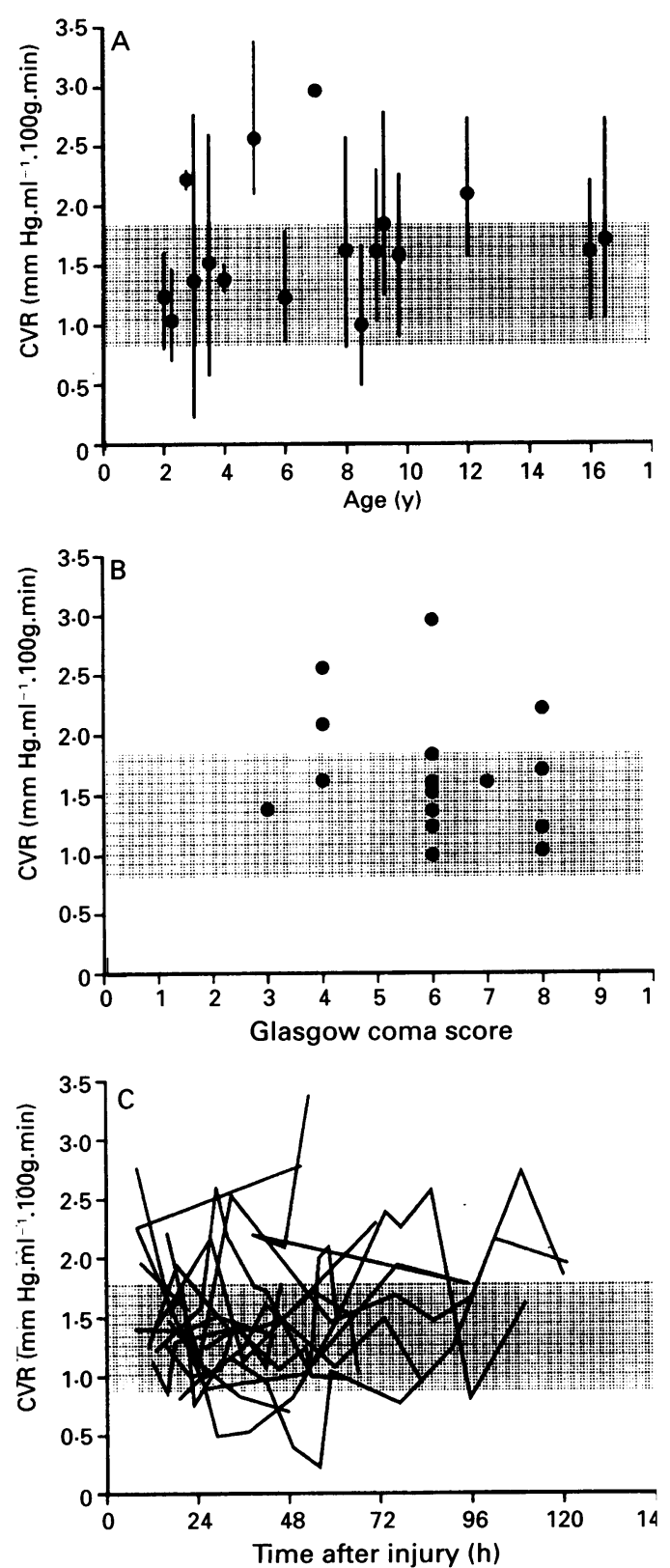

catheter connected to an externally mounted pressure transducer (Viggo-Spectramed, Swindon, UK) and in 13, by a subarachnoid catheter with a Camino transducer on its tip. ${ }^{14}$ Systemic arterial pressure was measured via an indwelling catheter sited in a peripheral artery and an externally mounted pressure transducer.

Cerebral perfusion pressure (CPP) was calculated from the equation:

$$
\mathrm{CPP}=\mathrm{MAP}-\mathrm{ICP}
$$

where MAP is the mean arterial blood pressure and ICP is the mean intracranial pressure.

Cerebrovascular resistance (CVR) was calculated from the equation:

$$
\mathrm{CVR}=\mathrm{CPP} / \mathrm{CBF}
$$

\section{Results}

One hundred and twenty two measurements of cerebrovascular resistance were performed. The mean time between injury and the first measurement was 18.9 (range $7 \cdot 3-50$ ) hours. The mean duration of each study was 74.2 (range 4-194) hours, and the mean number of measurements performed in each subject was 7 (range 1-18).

\section{CEREBROVASCULAR RESISTANCE}

Figure 1A shows the mean value and range of cerebrovascular resistance for each subject. Values for cerebrovascular resistance varied considerably both between and within patients. There was no correlation between mean cerebrovascular resistance and age $(\mathrm{n}=$ $17, r=0.15, p=0.58$; fig $1 \mathrm{~A}$ ), the patient's Glasgow coma score on admission $(n=17$, $r=-0.21, \mathrm{p}=0.42 ;$ fig $1 \mathrm{~B})$, or time after injury (fig 1C) (paired $t$ test on results obtained on the first and third days after injury, $p=0 \cdot 28 ; n=13$ ).

There are no published data for cerebrovascular resistance in normal children, so the range obtained by Scheinberg and Stead in normal adults ${ }^{15}$ has been used for comparison; these results were obtained in unanaesthetised 
Figure 2 (A) Relation between cerebrovascular resistance $(C V R)$ and cranial perfusion pressure (CPP) for all 122 resuilts obtained from the 17

patients. Each patient is identified by a different symbol. (B) relation between CVR and CPP for results obtained from the 13 children with a good or moderate outcome; $(C)$ relation between these variables for the four children who died or survived with considerable handicap.
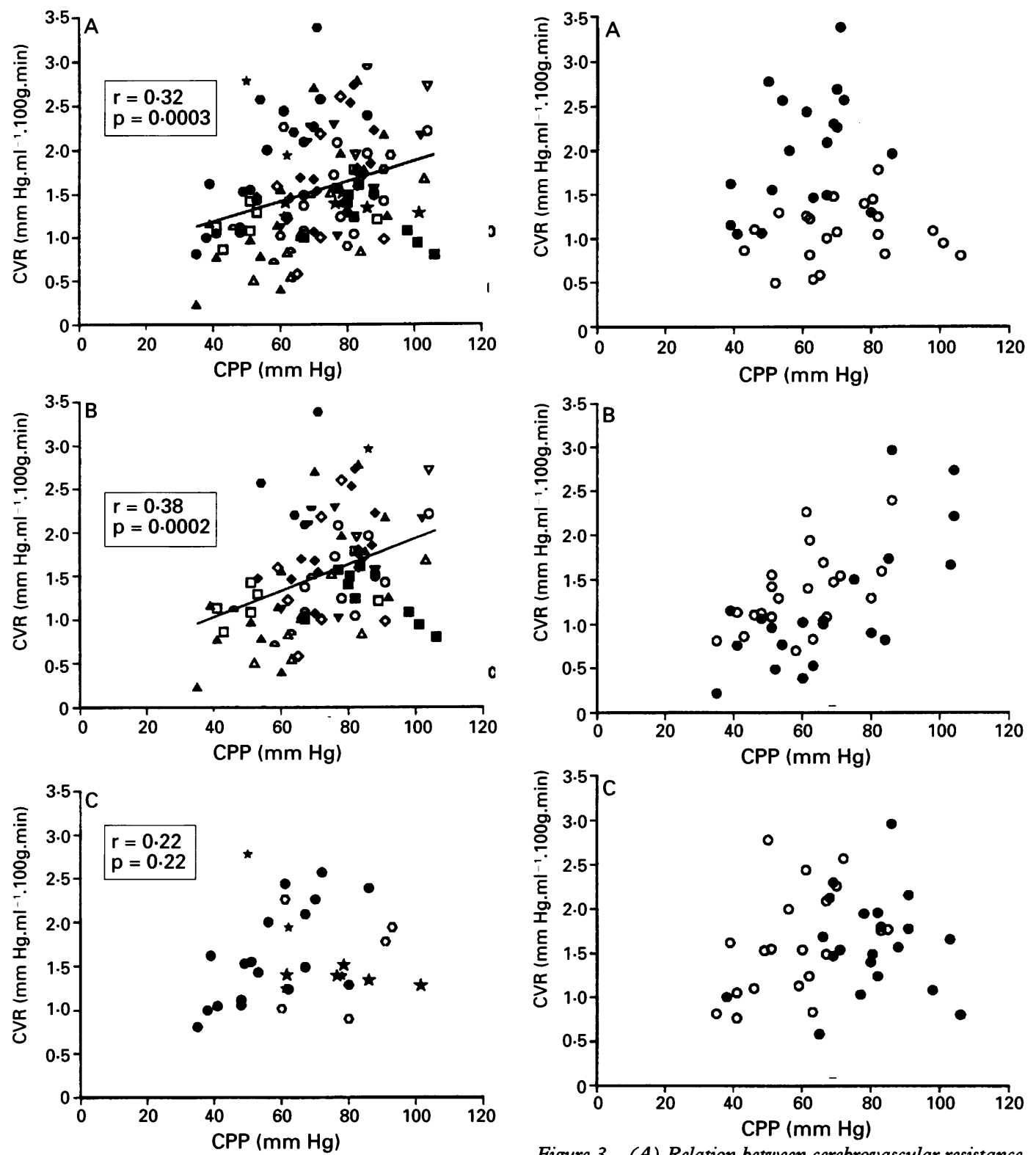

subjects and are similar to the values obtained by other workers. ${ }^{16}$ The cerebrovascular resistance for our patients (mean $1.54 \mathrm{~mm} \mathrm{Hg}$. $\mathrm{ml}^{-1} .100$ g.min (SD 0.61 ) was higher than that reported in normal subjects by Scheinberg and Stead (mean cerebrovascular resistance $1.31 \mathrm{~mm} \mathrm{Hg} \cdot \mathrm{ml}^{-1} .100$ g.min (SD $0 \cdot 24)) .{ }^{15}$ Seventy one $(58 \%)$ of the 122 cerebrovascular resistance values fell within the normal range, $39(32 \%)$ were above the normal range, and only $12(10 \%)$ were below the normal range.

\section{DETERMINANTS OF CEREBROVASCULAR RESISTANCE}

\section{Pressure autoregulation}

Figure 2A illustrates the relation between cerebral perfusion pressure and cerebrovascular resistance. Overall, there was a significant correlation between cerebral perfusion pressure and cerebrovascular resistance (number of patients $=17$, number of observations $=$ $122, r=0.32, p=0.0003)$. When the children were subdivided into those with good or moderate outcomes and those with poor outcomes, the significant relation between cere-

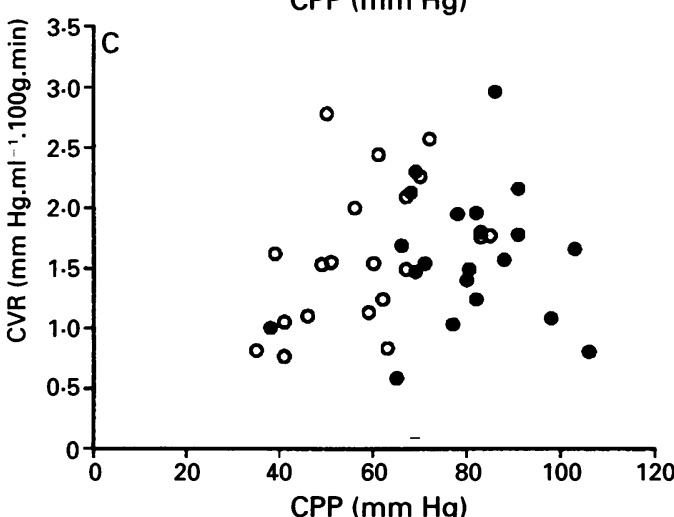

Figure 3 (A) Relation between cerebrovascular resistance (CVR) and cranial perfusion pressure (CPP) for results associated with high and low $\mathrm{CMRO}_{2}$ results; (B), high and low $\mathrm{AO}_{2}$ results; (C) high and low $\mathrm{PaCO}$ results. In

(A) results associated with $\mathrm{CMRO}_{2}$ values $1 S D$ deviation above the group mean (high $\mathrm{CMRO}_{2}$, number of observations $=20$, number of patients $=9$ ) are represented by open symbols and results associated with $\mathrm{CMRO}_{2}$ values $1 S D$ below the group mean (low $\mathrm{CMRO}_{2}$, number of observations $=19$, number of patients $=7$ ) by filled symbols. There is a significant difference between cardiovascular resistance (CVR) results associated with high $\mathrm{CMRO}_{2}$ values and those associated with low $\mathrm{CMRO}_{2}$ values (Student's $t$ test, $p=0.0001$ ). In (B) results associated with $\mathrm{AO}_{2}$ values $1 \mathrm{SD}$ above the group mean (high $\mathrm{AO}_{2}$, number of observations $=20$, number of patients $=7$ ) are represented by filled symbols and results associated with $\mathrm{AO}_{2}$ values $1 \mathrm{SD}$ below the group mean low $\mathrm{AO}_{2}$, number of observations $=22$, number of patients $=8$ ) by open symbols. There is no significant difference between CVR results associated with high $\mathrm{AO}_{2}$ values and those associated with low $\mathrm{AO}_{2}$ values

(Student's $t$ test, $p=0 \cdot 35$ ). In (C) results associated with $\mathrm{PaCO}_{2}$ values $1 \mathrm{SD}$ above the group mean (high $\mathrm{PaCO}_{2}$ number of observations $=21$, number of patients $=11$ ) are represented by filled symbols and $\mathrm{PaCO}_{2}$ results $1 \mathrm{SD}$ below the group mean (low $\mathrm{PaCO}_{2}$, number of observations $=20$, number of patients $=5$ ) by open symbols. There is no significant difference between CVR results associated with high $\mathrm{PaCO}_{2}$ values and those associated with low $\mathrm{PaCO}_{2}$ values (Student's t test, $p=0.92$ ).

bral perfusion pressure and cerebrovascular resistance was maintained in those with good or moderate outcomes (number of patients = 
13, number of observations $=89, r=0 \cdot 38, p$ $=0.0002$; fig $2 \mathrm{~B}$ ), but there was no overall correlation between cerebral perfusion pressure and cerebrovascular resistance for those who died or had a poor neurological outcome (number of patients $=4$, number of observations $=33, r=0 \cdot 22, \mathrm{p}=0 \cdot 22$ ).

\section{Chemical autoregulation}

For all patients, there was wide variability in the cerebrovascular resistance results obtained at any level of cerebral perfusion pressure (fig 2A). To investigate whether this variability was related to other factors which would also normally determine cerebrovascular resistance-namely, $\mathrm{CMRO}_{2}, \mathrm{PaCO}_{2}$, and $\mathrm{AO}_{2}{ }^{16-20}$ - the correlation was repeated, but this time with only results that were either $1 \mathrm{SD}$ below, or $1 \mathrm{SD}$ above, the mean value for the group as a whole for each of these variables.

Figure 3A compares the relation between cerebrovascular resistance and cerebral perfusion pressure for results that were associated with $\mathrm{CMRO}_{2}$ values greater than $1 \mathrm{SD}$ above the group mean $\left(\mathrm{CMRO}_{2}>1.31 \mu \mathrm{mol}\right.$. $\left.\mathrm{g}^{-1} \cdot \mathrm{min}^{-1}\right)$ and those more than $1 \mathrm{SD}$ below the mean $\left(\mathrm{CMRO}_{2}<0.35 \mu \mathrm{mol} . \mathrm{g}^{-1} \cdot \mathrm{min}^{-1}\right)$. For those measurements when $\mathrm{CMRO}_{2}$ was 1 $\mathrm{SD}$ above the mean, the cerebrovascular resistance (number of observations $=20$, number of patients $=9$, mean cerebrovascular resistance $1.07 \mathrm{~mm} \mathrm{Hg} \cdot \mathrm{ml}^{-1} .100 \mathrm{~g} . \mathrm{min}$ (SD 0.56) was significantly lower than for those measurements associated with a $\mathrm{CMRO}_{2} 1 \mathrm{SD}$ below the mean (number of observations = 19 , number of patients $=7$, mean cerebrovascular resistance $1.85 \mathrm{~mm} \mathrm{Hg} \cdot \mathrm{ml}^{-1} .100 \mathrm{~g} \cdot \mathrm{min}$ (SD 0.56) (Student's $t$ test, $\mathrm{p}=0.0001$ ).

Variations in $\mathrm{AO}_{2}$ and $\mathrm{PaCO}_{2}$ altered the nature of the relation between cerebral perfusion pressure and cerebrovascular resistance to a much lesser extent than variations in $\mathrm{CMRO}_{2}$.

Figure 3B compares the relation between cerebral perfusion pressure and cerebrovascular resistance for those results associated with $\mathrm{AO}_{2}$ content more than $1 \mathrm{SD}$ above the group mean $\left(\mathrm{AO}_{2}>7.5 \mu \mathrm{mol} . \mathrm{ml}^{-1}\right)$ and those more than $1 \mathrm{SD}$ below the mean $\left(\mathrm{AO}_{2}<5.4 \mu \mathrm{mol}\right.$. $\mathrm{ml}^{-1}$ ). For those measurements in which the $\mathrm{AO}_{2}$ was greater than $1 \mathrm{SD}$ above the mean, cerebrovascular resistance was higher (number of observations $=20$; number of patients $=7$; mean cerebrovascular resistance 1.36 $\mathrm{mm} \mathrm{Hg} \cdot \mathrm{ml}^{-1} .100$ g.min (SD 0.61)) than for those associated with $\mathrm{AO}_{2}$ more than $1 \mathrm{SD}$ below the mean (number of observations = 22 , number of patients $=8$, mean cerebrovascular resistance $1.19 \mathrm{~mm} \mathrm{Hg} \cdot \mathrm{ml}^{-1} .100$ g.min (SD 0.61)), but the difference was not statistically significant (Student's $t$ test, $\mathrm{p}=0 \cdot 35$ ).

Figure 3C compares the relation between cerebral perfusion pressure and cerebrovascular resistance for those results associated with a $\mathrm{PaCO}_{2}$ greater than $1 \mathrm{SD}$ above the group mean $\left(\mathrm{PaCO}_{2}>4.4 \mathrm{kPa}\right)$ and those greater than $1 \mathrm{SD}$ below the mean $\left(\mathrm{PaCO}_{2}<3.4 \mathrm{kPa}\right)$. Higher $\mathrm{PaCO}_{2}$ values were not associated with significantly lower cerebrovascular resistance results (number of observations $=21$, number
Table 2 Multilevel analysis of factors that may determine cerebrovascular resistance

\begin{tabular}{lll}
\hline Variable & $t$ Value & $p$ Value \\
\hline $\mathrm{CMRO}_{2}\left(\mu \mathrm{mol} . \mathrm{g}^{1} \cdot \mathrm{min}^{-1}\right)$ & -6.36 & $<0.0001$ \\
$\mathrm{CPP}(\mathrm{mm} \mathrm{Hg})$ & +5.30 & $<0.0001$ \\
$\left.\mathrm{AO}_{2}\left(\mu \mathrm{mol}^{-1}\right)^{-1}\right)$ & $+2 \cdot 28$ & $<0.05$ \\
$\mathrm{Cerebrovenous} \mathrm{pH}^{\mathrm{PaCO}_{2}(\mathrm{kPa})}$ & -1.76 & $<0.05$ \\
$\mathrm{Time}^{2}$ after injury & -1.59 & $<0.05$ \\
Cerebrovenous lactate concentration & +0.95 & $\mathrm{NS}$ \\
& -0.12 & $\mathrm{NS}$ \\
\hline
\end{tabular}

CPP = Cerebral perfusion pressure.

of patients $=11$, mean cerebrovascular resistance $1.59 \mathrm{~mm} \mathrm{Hg} \cdot \mathrm{ml}^{-1} .100 \mathrm{~g} \cdot \mathrm{min}$ (SD $0 \cdot 12)$ ) than those associated with the lower $\mathrm{PaCO}_{2}$ values (number of observations $=20$, number of patients $=5$, mean cerebrovascular resistance $1.62 \mathrm{~mm} \mathrm{Hg} \cdot \mathrm{ml}^{-1} .100$ g.min (SD $0 \cdot 13$ ); Student's $t$ test, $\mathrm{p}=0.92$ ).

The results suggest that $C M \mathrm{MO}_{2}$ remains an important determinant of cerebrovascular resistance in children with severe head injuries and that the normal relation between cerebral metabolic rate and cerebral blood flow is preserved. Figure 4 illustrates the relation between cerebral blood flow and $\mathrm{CMRO}_{2}$ for all the study subjects. Overall, there was a close correlation between cerebral blood flow and $\mathrm{CMRO}_{2}$ (number of observations $=122$, number of patients $=17, \quad r=0.56, \quad \mathrm{p}<$ 0.0001 ), suggesting that metabolic autoregulation was intact. ${ }^{4}$

ANALYSIS BY MULTILEVEL MODELLING

To determine which variables were independent determinants of cerebrovascular resistance, and to assess their relative importance, analysis by multilevel modelling was performed. ${ }^{21}$ This hierarchial system of data analysis is based on the principles of multiple regression analysis but allows for each patient contributing multiple results. The contribution to the variation in cerebrovascular resistance that could be attributed to interpatient variability was found to be small, with the between patient variance estimated as zero in most cases. The cerebrovenous lactate concentration, $\mathrm{CMRO}_{2}$, cerebral perfusion pressure, $\mathrm{AO}_{2}, \mathrm{PaCO}_{2}$, and time after injury were regressed on cerebrovascular resistance; $\mathrm{CMRO}_{2}$, cerebral perfusion pressure, $\mathrm{AO}_{2}$, $\mathrm{PaCO}_{2}$ and cerebrovenous $\mathrm{pH}$ emerged as significant independent determinants of

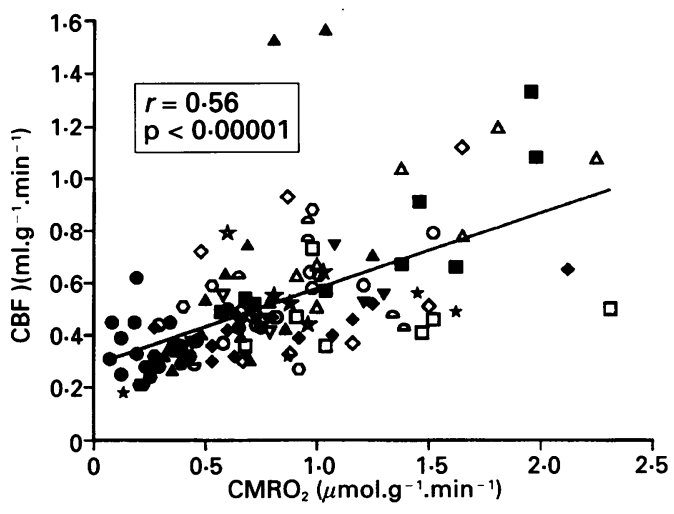

Figure 4 Relation between $\mathrm{CMRO}_{2}$ and cerebral blood flow for all the 122 results obtained from 17 patients. 
cerebrovascular resistance, by contrast with time after injury and cerebrovenous lactate concentration, which did not emerge as independent determinants (table 2).

\section{Discussion}

This study is the first to attempt to explore the relative importance of the factors that determine cerebrovascular resistance in children with severe head injuries. Experimental studies in animals by Langfitt et al led to the suggestion that in those with brain injuries the cerebral circulation may be "vasospastic" with a severely impaired response to normal physiological control mechanisms ${ }^{22}{ }^{23}$ and Lassen proposed that this might be due to high levels of brain lactic acid. ${ }^{24}$ The concept of "vasospastic paralysis" was cited by Bruce and colleagues to account for the normal or increased cerebral blood flow that they reported in a few children with head injuries. ${ }^{625}$ Our results suggest, however, that the cerebral circulation is not vasospastic in most children with head injuries. The cerebrovenous concentration of lactate did not emerge as an independent determinant of cerebrovascular resistance in our patients.

In a healthy brain, cerebral blood flow is maintained constant, at a level appropriate for cerebral metabolic needs, regardless of changes in cerebral perfusion pressure (pressure autoregulation). This is achieved because variations in cerebral perfusion pressure within the autoregulatory range (about 50-150 mm $\mathrm{Hg}$ ) are accompanied by compensatory alterations in cerebrovascular resistance. ${ }^{1726}$ The finding in the present study of a significant correlation between cerebral perfusion pressure and cerebrovascular resistance thus suggests that pressure autoregulation in the patients is often intact. This finding is in accordance with that of Muizelaar et al, who investigated the status of pressure autoregulation by measuring cerebrovascular resistance before and after an elective change in cerebral perfusion pressure and judged autoregulation to be intact in $22(59 \%)$ of 37 measurements. ${ }^{5}$ It is also in keeping with the findings of workers who have studied mainly adult patients. ${ }^{27-29}$

The finding that $\mathrm{CMRO}_{2}$ was a powerful determinant of cerebrovascular resistance indicates that cerebral blood flow and metabolism are often appropriately coupled, even in children with severe head injuries. Similarly, Obrist et al and Cold concluded that metabolic autoregulation was preserved in $45 \%$ and $56 \%$, respectively, of the predominantly adult patients with head injuries that they studied. ${ }^{4}{ }^{30}$ By contrast, Muizelaar et al, in the only other large study of cerebral blood flow in children with head injuries, concluded that there was metabolic uncoupling after trauma. ${ }^{31}$ The conclusions of Muizelaar and colleagues echoed those of Bruce et al, based on measurements of cerebral blood flow and $\mathrm{CMRO}_{2}$ in six patients. ${ }^{62}$ Cerebrovascular $^{25}$ resistance and $\mathrm{CMRO}_{2}$ have a common variable - namely, cerebral blood flow. The strong correlation noted, however, between cerebrovascular resistance and $\mathrm{CMRO}_{2}$ is unlikely simply to be due to this, as cerebral blood flow and $\mathrm{CMRO}_{2}$, which also share a common variable, have been noted often not to be correlated in adult patients with head injuries. ${ }^{4} 30$

The discrepancy between the results reported by Muizelaar et al concerning metabolic autoregulation and the findings in our present study may have resulted from Muizelaar et al studying more seriously injured children; the mean Glasgow coma score on admission in their study was 5.4 $(1 \cdot 2), 21 \%$ of the subjects had bilateral fixed dilated pupils, $10 \%$ had a unilaterally fixed and dilated pupil, and in $21 \%$ of the children oculocephalic responses were severely disturbed or absent. ${ }^{31}$ On the other hand, the discrepancy may simply arise from a difference in interpretation.

Muizelaar et al based their conclusion that cerebral blood flow and metabolism were uncoupled largely on values for the arteriojugular venous oxygen difference $\left(\mathrm{AJVDO}_{2}\right)$, which reflects the balance between $\mathrm{CMRO}_{2}$ and cerebral blood flow (CBF) $\left(\mathrm{AJVDO}_{2}=\right.$ $\left.\mathrm{CMRO}_{2} / \mathrm{CBF}\right)^{412} \mathrm{~A}$ low $\mathrm{AJVDO}_{2}$ indicates that cerebral blood flow is in relative excess for cerebral metabolic needs, and Muizelaar $e t$ $a l^{31}$ reported that the $\mathrm{AJVDo}{ }_{2}$ values obtained in their patients were low in comparison with those published in normal adults by Kety and Schmidt. ${ }^{11}$ The $\mathrm{AJVDO}_{2}$ values obtained by Kety and Schmidt in adults, however, are higher than those obtained in normal children by Settergren et $a l^{32}$ and Kennedy and Solokoff. ${ }^{33}$ Had Muizelaar et al compared their $\mathrm{AJVDO}_{2}$ results with those obtained in normal children, almost all the results would have been in the normal range indicating normal coupling of cerebral blood flow and metabolism. Moreover, the $\mathrm{AJVDO}_{2}$ results published by Muizelaar et al represent raw data "corrected" to allow for a reduction in cerebral blood flow with hyperventilation and reduced arterial $\mathrm{PaCO}_{2}{ }^{31}$ Such a correction would lead to an apparent lowering of $\mathrm{AJVDO}_{2}$. The practice of correcting for $\mathrm{PaCO}_{2}$ in hyperventilated patients is hard to justify in the light of experimental evidence that the cerebral circulation adapts to a low $\mathrm{PCO}_{2}$ if hyperventilation is prolonged beyond 24 hours, cerebral blood flow returning to its baseline value or even above. ${ }^{34}$

Despite the recognised importance of $\mathrm{AO}_{2}$ as a determinant of cerebrovascular resistance in normal subjects, ${ }^{20}$ we are not aware of any previous clinical studies that have explored the relation between arterial oxygen content and cerebrovascular resistance or cerebral blood flow in patients with head injuries. An experimental study in cats by Lewelt et al has suggested that concussive brain injury interfered with the normal vasodilator response of the cerebral circulation to hypoxaemia, but cerebrovascular resistance was only investigated up to one hour after injury. ${ }^{35}$

The fact that $\mathrm{AO}_{2}$ emerged as an independent determinant of cerebrovascular resistance in children with severe head injuries 
emphasises the importance of maintaining a normal haemoglobin in these patients, as well as a normal $\mathrm{PaCO}_{2}$, as the most important determinant of $\mathrm{AO}_{2}$ under atmospheric conditions is the haemoglobin concentration. It could be hypothesised that a change in haemoglobin concentrations might alter cerebral blood flow by altering blood viscosity as well as by altering $\mathrm{AO}_{2}{ }^{2036}$ Brown and colleagues have shown, however, that blood viscosity alone does not have an independent effect on cerebral blood flow. ${ }^{20} 36$

In the present study $\mathrm{PaCO}_{2}$ emerged as a relatively weak determinant of cerebrovascular resistance. This was an unexpected finding, as studies of $\mathrm{CO}_{2}$ responsivity in adult patients, performed by measuring cerebral blood flow before and after a stepwise alteration in $\mathrm{PaCO}_{2}$, have suggested that $\mathrm{CO}_{2}$ autoregulation is almost always preserved after head injury. ${ }^{28}{ }^{3738} \mathrm{It}$ is in accordance with the findings in normal subjects by Brown and colleagues, who reported that $\mathrm{AO}_{2}$ was a more powerful determinant of cerebrovascular resistance than $\mathrm{PaCO}_{2}{ }^{20}$

An explanation for the finding that $\mathrm{PaCO}_{2}$ was a weaker determinant of cerebrovascular resistance than $\mathrm{AO}_{2}$ might be the progressive adaptation of cerebrovascular resistance to chronic hypocapnia, which has recently been shown to occur in normal rabbits after prolonged hyperventilation. ${ }^{34}$ This would lead to a poor overall correlation between $\mathrm{PaCO}_{2}$ and cerebrovascular resistance, even though the cerebrovascular circulation was still able to respond normally to an acute change in $\mathrm{PaCO}_{2}{ }^{34}$

Many of the cerebral blood flow measurements in this study were made in children who had been subjected to a prolonged period of artificial ventilation.

The finding that cerebrovenous $\mathrm{pH}$ was a significant negative determinant of cerebrovascular resistance was unexpected, as a high cerebrovenous $\mathrm{pH}$, resulting from a low arterial $\mathrm{PaCO}_{2}$, has been shown to cause increased cerebrovascular resistance and reduced cerebral blood flow. As the effect of the multilevel model is to control for the effect of $\mathrm{PaCO}_{2}$ on cerebrovascular resistance, allowing the relation between cerebrovenous $\mathrm{pH}$ and cerebrovascular resistance to be viewed in isolation, however, it is possible that the negative relation between cerebrovenous $\mathrm{pH}$ and cerebrovascular resistance is due to the fact that children with a poor outcome produced significantly more cerebral lactate and therefore had lower cerebrovenous $\mathrm{pH}$ results. Although overall there was no significant difference between the cerebrovascular resistance values obtained from children with a poor outcome compared with the results obtained from those with a good or moderate outcome, there was a non-significant tendency for cerebrovascular resistance results to be higher in children who had a poor eventual outcome.

The results of this study suggest that normal autoregulatory mechanisms, particularly metabolic autoregulation, are preserved in most children with post-traumatic encephalopathy, but the lack of correlation between cerebral perfusion pressure and cerebrovascular resistance in those children who died or had a poor outcome suggests that there is a subpopulation of patients in whom pressure autoregulation is disturbed. These patients may be particularly vulnerable to cerebral ischaemia, a hypothesis supported to some extent by the evidence suggesting an association between impaired cerebrovascular reactivity and outcome. It therefore seems reasonable to hypothesise that outcome might be improved if such particularly vulnerable patients are prospectively identified and the adequacy of cerebral blood flow for cerebral metabolic demands closely monitored by methods such as continuous monitoring of the jugular oxygen saturation. ${ }^{39} 40$

It has often been stated that the pathophysiology of traumatic encephalopathy in children differs from that in adults, ${ }^{162531}$ principally because low cerebrovascular resistance results in hyperaemia, diffuse cerebral swelling, and raised intracranial pressure. This hypothesis is not supported by the results of the present study, which showed that in most cases cerebrovascular resistance was either within, or above, the normal range. The cerebrovascular resistance values reported in this paper represent "raw" data, which have not been corrected to a normative arterial $\mathrm{PaCO}_{2} \cdot{ }^{731}$ Even if the results are corrected to a normative $\mathrm{PaCO}_{2}(39 \mathrm{~mm} \mathrm{Hg})$ however, 87 of $122(71 \%)$ still fall above or within the normal range, whereas only 35 of $122(29 \%)$ fall below the lower limit of the range. Despite suggestions that cerebral hyperaemia is more common in the youngest children ${ }^{2}$ there was no evidence of a correlation between cerebrovascular resistance and age. The finding that cerebrovascular resistance is usually normal or increased after severe head injury in children is in accordance with the findings of workers whose studies have mainly involved adults. ${ }^{41-44}$ These findings provide further evidence to suggest that the pathophysiology of traumatic encephalopathy in children is not essentially different from that in adults.

We thank the parents of the children, the medical and nursing staff of the intensive care unit, the consultant neurosurgeons who allowed us to study their patients, Dr J N S Matthews for statistical advice, and Miss A McGann for technical assistance. We acknowledge financial support from Action Research, the Newcastle Health Authority, the Wellcome Trust, the Medical Rescarch Council, and the Mason Medical Foundation.

1 Pascucci RC. Head trauma in the child. Intensive Care Med 1988;14:185-95.

2 Bruce DA, Langfitt TW, Miller JD, et al. Regional cerebral blood flow, intracranial pressure, and brain metabolism in comatose patients. $\mathcal{F}$ Neurosurg 1973;38:131-44.

3 Overgaard J, Tweed WA. Cerebral circulation after head injury. Part 1: cerebral blood flow and its regulation after closed head injury and emphasis on clinical correlations. f Neurosurg 1974;41:531-41.

4 Obrist WD, Langfitt TW, Jaggi JL, Cruz J, Gennarelli TA Cerebral blood flow and metabolism in comatose patients with acute head injury. Relationship to intracranial hypertension. 7 Neurosurg 1984;61:241-53.

5 Muizelaar JP, Ward JD, Marmarou A, Newlon PG, Wachi A. Cerebral blood flow and metabolism in severely head injured children. Part 2: autoregulation. 7 Neurosurg 1989;71:72-6.

6 Bruce DA, Raphaely RC, Goldberg AI, et al. Pathophysiology, treatment and outcome following severe 
head injury in childhood. Child's Brain 1979;5: 174-91.

7 Sharples PM, Stuart AG, Matthews D, Aynsley-Green A Eyre JA. Cerebral blood flow and metabolism in children with severe head injuries. Part 1: relation to age, Glasgow coma score, outcome, intracranial pressure, and time after injury. $f$ Neurol Neurosurg Psychiatry and time after

8 Teasdale G, Jennett B. Assessment of coma and impaired consciousness. Lancet 1974;ii:81-4.

9 Berger MS, Pitts LH, Lovely M, Edwards MSB, Bartkowski HM. Outcome from severe head injury in children and adolescents. $\mathcal{F}$ Neurosurg 1985;62:194-9.

10 Tasker RC, Matthew DJ, Helms P, Dinwiddie R, Boyd S Monitoring in non-traumatic coma. Part 1: invasive intracranial measurements. Arch Dis Child 1988;63: 888-94.

11 Kety SS, Schmidt CF. The nitrous oxide method for the quantitative determination of cerebral blood flow in man: theory, practice and normative values. 7 Clin Invest 1948;27:476-83.

12 Sharples PM, Stuart AG, Aynsley-Green A, et al. A practical method of serial bedside measurement of cerebral blood flow and metabolism during neurointensive care. Arch Dis Child 1991;66:1326-32.

13 Harrison J, Hodson AW, Skillen AW, et al. Blood glucose, lactate, pyruvate, glycerol, 3-hydroxybutyrate and acetoacetate measurements in man using a fast centrifugal analyser with fluorometric attachment. fournal of Clinical Chemistry and Clinical Biochemistry 1988;26:141-6.

14 Chambers IR, Mendelow AD, Sinar EJ, Modar P. A clinical evaluation of the camino subdural screw and ventricular monitoring kits. Neurosurgery 1990;26:421-3.

15 Scheinberg P, Stead EA. The cerebral blood flow in male subjects as measured by the nitrous oxide technique. Normal values for blood flow, oxygen utilisation, glucose utilisation, and peripheral resistance, with observations on the effect of tilting and anxiety. 7 Clin Invest 1949; 28:1163-71.

16 Kety SS, Schmidt CF. The effects of altered arterial tensions of carbon dioxide and oxygen on cerebral blood flow and cerebral oxygen consumption of normal young men. $\mathcal{F}$ Clin Invest 1948;27:484-91.

17 Lassen NA. Cerebral blood flow and oxygen consumption in man. Physiol Rev 1959;39:183 238 .

18 Cohen PJ, Alexander SC, Smith TC, Reivich M, Wollman $\mathrm{H}$. Effects of hypoxia and normocarbia on cerebra blood flow and metabolism in conscious man. $\mathcal{F} A p p$ Physiol 1967;23:183-9.

19 Wollman H, Smith TC, Stephen GW, et al. Effects of extremes of respiratory and metabolic alkalosis on cerebral blood flow in man. 7 Appl Physiol 1968;24:60-5.

20 Brown MM, Wade JPH, Marshall J. Fundamental importance of arterial oxygen content in the regulation importance of arterial oxygen content in the regulation

21 Goldstein $H$. Efficient statistical modelling of longitudinal data. Ann Hum Bio 1986;13:129-41.

22 Langfitt TW, Weinstein JD, Kassell NF. Cerebral vasomotor paralysis produced by intracranial hypertension. Neurology 1965;15:622-41.

23 Langfitt TW, Tannenbaum HM, Kassell NF. The etiology of acute brain swelling following experimental brain injury. $\mathcal{F}$ Neurosurg 1966;24:47-56.

24 Lassen NA. The luxury-perfusion syndrome and its possible relation to acute metabolic acidosis localised within the brain. Lancet 1966;ii:1113-5.

25 Bruce DA, Alavi A, Bilaniuk L, et al. Diffuse cerebral swelling following head injuries in children: the syndrome of "malignant brain oedema". $f$ Neurosurg 1981; 54:170-8.
26 Bruce DA. Cerebrovascular dynamics. In: James HE, Anas NG, Perkin RM, eds. Brain insults in infants and children. Orlando: Grune and Stratton Inc, 1985:53-7.

27 Fieschi C, Battistini N, Beduschi A, et al. Regional cerebral blood flow and intraventricular pressure in acute head injuries. $\mathcal{F}$ Neurol Neurosurg Psychiatry 1974; 37:1378-88.

28 Enevoldsen EM, Jensen FT. Autoregulation and $\mathrm{CO}_{2}$ responses of cerebral blood flow in patients with acute brain injury. $f$ Neurol Neurosurg Psychiatry 1974;37: 1378-88.

29 Enevoldsen EM, Cold G, Jensen FT, et al. Dynamic changes in regional CBF, intraventricular pressure, CSF $\mathrm{pH}$ and lactate levels during the acute phase of head injury. $\mathcal{F}$ Neurosurg 1976;44:191-214.

30 Cold GE. The relationship between cerebral metabolic rate of oxygen and cerebral blood flow in the acute phase of head injury. Acta Anaesthesiol Scand 1986;30:453-7.

31 Muizelaar JP, Marmarou A, DeSalles AAF, et al. Cerebral blood flow and metabolism in severely head injured children Part 1: relationship with GCS score, outcome, ICP and PVI. $\mathcal{F}$ Neurosurg 1989;71:63-71.

32 Settergren G, Linblad BS, Persson B. Cerebral blood flow and exchange of oxygen, glucose, ketone bodies, lactate, pyruvate and amino acids in anaesthetised children. Acta pyruvate and amino acids in anaesthetised
Paediatrica Scandinavica $1980 ; 69: 457-65$.

33 Kennedy C, Sokoloff L. An adaptation of the nitrous oxide method to the study of the cerebral circulation in children; normal values for cerebral blood flow and cerebral metabolic rate in childhood. F Clin Invest 1957;36: 1130-7.

34 Muizelaar JP, van der Poel HG, Zhongchao L, Kontos HA, Levasseur JE. Pial arteriolar vessel diameter and $\mathrm{CO}_{2}$ reactivity during prolonged hyperventilation in the rabbit. $\mathcal{F}$ Neurosurg 1988;69:923-7.

35 Lewelt W, Jenkins LW, Miller JD. Effects of experimental fluid-percussion injury of the brain on cerebrovascular reactivity to hypoxia and to hypercapnia. $\mathcal{f}$ Neurosurg 1982;56:332-8.

36 Brown MM, Marshall J. Regulation of cerebral blood flow in response to changes in blood viscosity. Lancet 1985; i.604-9.

37 Cold GE, Jensen FT, Malmros R. The effect of $\mathrm{PaCO}_{2}$ reduction on regional cerebral blood flow in the acute phase of brain injury. Acta Anaesthesiol Scand 1977;21: 359-67.

38 Saunders ML, Miller JD, Stablein D, et al. The effects of graded experimental trauma on cerebral blood flow and responsiveness to $\mathrm{CO}_{2}$. $\mathcal{F}$ Neurosurg 1979;51:18-26.

39 Cruz J, Milner ME, Allen SJ, Alves WM, Gennarelli TA. Continuous monitoring of cerebral oxygenation in acute brain injury: injection of mannitol during hyperventilation. $\mathcal{F}$ Neurosurg 1990;73:725-30.

40 Sheinberg M, Kanter MJ, Robertson CS, et al. Continuous monitoring of jugular venous oxygen saturation in head injured patients. $\Im$ Neurosurg 1992;76:212-7.

41 Obrist WD, Gennarelli TA, Segwa H, Dolinskas CA, Langfitt TW. Relation of cerebral blood flow to neurological status and outcome in head injured patients. $\mathcal{f}$ logical status and outcome

42 Overgaard J, Tweed WA. Cerebral circulation after head injury. Part 2: the effects of traumatic brain edema. $\mathcal{F}$ Neurosurg 1976;45:292-300.

43 Tabaddor $\mathrm{K}$, Bhushan $\mathrm{C}$, Pevsner PH, Walker AE. Prognostic value of cerebral blood flow (CBF) and cerebral metabolic rate of oxygen $\left(\mathrm{CMRO}_{2}\right)$ in acute head trauma. F Trauma 1973;12:1053-5.

44 Meyer JS, Kondon A, Nomura F, Sakamoto K, Teraura $\mathrm{T}$. Cerebral hemodynamics and metabolism following experimental head injury. $\mathcal{F}$ Neurosurg 1970;32:304-19. 